\title{
Selective Separation of Lead lons Using New Nano-Adsorbent GH-92
}

\author{
Ensieh Khodadad Hosseini", Hossein Ghafourian, Mohammad Rabbani \\ Marine Chemistry Department, Faculty of Marine Science and Technology, Islamic Azad University, Tehran, Iran \\ Email address: \\ ensiyehosainy@yahoo.com (E. K. Hosseini), h_ghafourian@iau-tnb.ac.ir (H. Ghafourian), mhd_rabani@yahoo.com (M. Rabbani) \\ ${ }^{*}$ Corresponding author
}

\section{To cite this article:}

Ensieh Khodadad Hosseini, Hossein Ghafourian, Mohammad Rabbani. Selective Separation of Lead Ions Using New Nano-Adsorbent GH92. International Journal of Computational and Theoretical Chemistry. Vol. 6, No. 1, 2018, pp. 14-20. doi: 10.11648/j.ijctc.20180601.12

Received: December 19, 2017; Accepted: January 2, 2018; Published: January 19, 2018

\begin{abstract}
One of the main sources of environment pollution is the industrial wastewater which contains heavy metals and can be found in many industries. If these heavy metals enter in the human body, would cause many health problems. On the other hand, different researches around the world show that nanotechnology is an effective way to remove pollutants. In this research, for the first time in the world, a type of natural sponge of Persian Gulf that has Nano holes has been used to remove the lead ion selectively from calcium, magnesium and cobalt ions in aqueous solution. The present study identified a sample belonging to the sponge of Demospongiae class. The aggregation of absorption in the sponge, contact time, particle size and by measuring environment's $\mathrm{pH}$ were measured. The results show this type of sponge, GH-92, is able to absorb different amounts of mentioned metal ions. Adsorption amount of calcium, magnesium and cobalt by this type of sponge was very small. The highest adsorption capacity belonged to lead ion in $\mathrm{pH}=4.5$ to 5 with mesh 230 which was 79.19 mg per gram of adsorbent. This is the highest adsorption capacity of lead comparison with reported articles for selective separation of lead ion.
\end{abstract}

Keywords: Sponge, Persian Gulf, Nano-Adsorbent, Heavy Metals, Electron Microscopy

\section{Introduction}

Industrial effluents loaded with heavy metals are a cause of serious hazards to human and other forms of life. However, conventional methods such as precipitation, ion exchange, electro dialysis, etc. used for the removal of heavy metals from wastewater, are often cost prohibitive having inadequate efficiencies at low metal ion concentration. Bio sorption can be considered as an alternative technology which has been proved as more efficient and economical for the removal of heavy metals from the industrial wastewater (Mazaheri and Tehrani, M, 2012) In these studies active carbon resulting from burning straw has been used in order to remove cadmium. Cesar et al (2004) have studied using husk to remove metals such as lead, that in these studies some modifications were done on adsorbents (Cesar, R. T. T, Sergio, L. C. F., and Marco, A. Z. 2004). Other cheap adsorbents like slug, metal wastes, rice husk charcoal, active alumina, sea salt; bitter olive skin and teak wood also have been used to remove heavy metals (Bhattacharya, et al, 2008). In another study, ash has been used to filter heavy metal ions, and efficiency of this adsorbent has been compared with activated carbon in removing heavy metals from aqueous solution (Cetin, s. and Pehliean, E, 2007). Other cheap adsorbents we can point to Sun flower husk and tangerine peel. Also, the possibility of using natural and cheap adsorbents like pine, oak and sheep's dried intestine has been studied [(Namasivaym, et al 2001) (Annadurai, et al 2002) (Batzia, F. A., and Sidiras, D. K. 2004) (Ozacar, et al. 2005) (Seader, J. D. and Henly, E. J. 2006) (Odoemelam, S. A., and Eddy, N. O. 2009) (Zavvar Mousavi, S and Arjmandi, A. 2009)]. Extensive studies also have been done on some adsorbents like chitosan Nano- particles and modified MCM-41 Nano- porous in the world [(Ekhlasi, L; et al 2011) (Heidari, A; . et al 2009)]. In this research a kind of sponge has been used for the first time as an adsorbent for ion of lead in water. In addition, the effect of influencing factors in adsorption process has been studied and examined. Sea sponges have been used as a source of pharmaceuticals [(Bhimba, et al 2013) (Lunder, et al 2012) (Senthilkumar, K., et al 2013)] and as a biological index in oil materials and its derivatives (Batista, D., et al 2013). Sponges are among the 
simplest multi-cellular organisms which all of them are different from each other and don't have fixed physical shape and they exist in different shapes. Their body is covered with pores. All sponges reside in water especially in sea water. There is no coordination between cells. All sponges can also arise again from some separate cells, they have high rehabilitative power. Sponges are classified in three groups of Calcarea, Hexacttinellida and Demospongiae. The purpose of this study is to assess the efficiency of Demospongiae sponge, GH-92, in adsorption lead as well as the effect of different parameters in adsorption capacity and percentage of this ion, which can be a suitable base for sponge's efficiency as a natural and biological adsorbent in adsorption process of metal ions.

\section{Materials and Methods}

Materials: for providing required standards and chemical solutions, salts of Merck Company with analytical grade have been used. $\mathrm{Ca}\left(\mathrm{NO}_{3}\right)_{2} \cdot 4 \mathrm{H}_{2} \mathrm{O}, \mathrm{Mg}\left(\mathrm{NO}_{3}\right)_{2} \cdot 6 \mathrm{H}_{2} \mathrm{O}$, $\mathrm{Co}\left(\mathrm{NO}_{3}\right)_{2} \cdot 6 \mathrm{H}_{2} \mathrm{O}, \mathrm{Pb}\left(\mathrm{NO}_{3}\right)_{2}, \mathrm{HNO}_{3}$, and deionized water.

Devices: atomic absorption spectroscopy device model no. AA240 made by VARIAN Company of Australia with air flame- acetylene and halo-cathode lamp; Scanning Electron microscope model no. S4160 made by HITACHI Company; Quantachrome device model Nova2000 made by USA, pHmeter model no. GP353 made by EDT Company with glassy electrode made by METROHM Company, EC-meter pencil portable model made by England JENWAY company; Shaker model no. CB631 (Incubator) made by Iranian FATER ELECTRONIC Company; digital scale model no. AJ100 made by METTLER Company, mill moulinex model GENIUS 2000, sieve with 70, 120 and 230- mesh grading and other glassy supplies of laboratory.

\subsection{Preparing of Adsorbent}

In this research that is undertaken for the first time in Iran and the world, by using a sponge (Figure 1) with following specifications:

Class: Demospongiae

Family: Niphatidot

Species: Amphimedon vividas

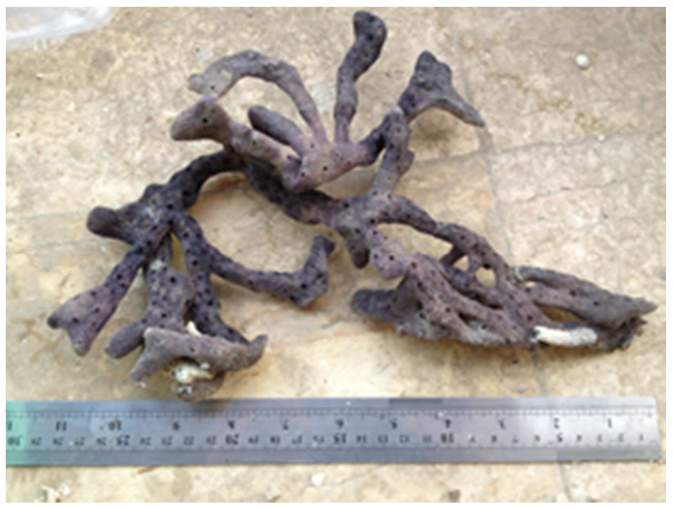

Figure 1. Demospongiae sponge (Niphatidot).
This sponge is collected from Kish Island, Persian Gulf. Sponge sampling was done through diving and investigation in 5-6 meters depth near Kish Island, Persian Gulf in 18-km Iranian southern shore, between geographic coordinates of 054 degree, $1 \mathrm{~min}$. and $108 \mathrm{~s}$ eastern length from Prime meridian, and 26 degree, $32 \mathrm{~min}$. and $857 \mathrm{~s}$. of northern width in September 2012 (Iranian date: Shahrivar month of 1391). Sponges have been separated from the floor to which they were attached and then sample was put in a sack. From sample, a small piece was cut and, in order to be identified, has been put in containers containing ethanol (Figure 2).

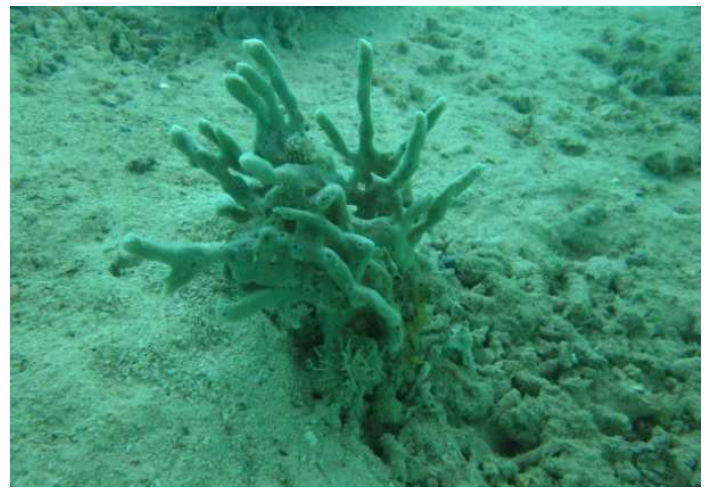

Figure 2. Demospongiae sponge in seabed from Kish Island.

In order to do the experiments, the interested sponge was divided into 10- gram pieces and after several times complete washing by distilled water, was dried in sun light in order to remove adsorbed ions of sea water. Sponges in two ways of pieces and powdered with 70, 120 and 230- mesh grading were used in order to remove aforementioned ion.

\subsection{Methodology}

0.1 gram weight of dried sponge was taken and in two forms of small pieces of sponge and powdered sponge with 70,120 and 230 mesh grading was put in a beaker and then $50 \mathrm{ml}$ volume of solution containing metal ions wad added. This solution containing metal ions has been studied in two ways of shaker and non-shaker for 1, 2, 3, 4, 6, 12 and 24 hours. Then, the solution under study was filtered and the amount of metal ions in solutions under the sieve has been measured by atomic absorption spectroscopy device with flame. All the performed experiments in this study were repeated 2 to 3 times according to the existent conditions and $\mathrm{pH}$ of medium was also measured. In order to prevent any error, all the containers being used were washed with acid and finally were washed with deionized distilled water. All the experiments were performed in room temperature.

\subsection{Determination of Adsorbent Nano-Particles Structure}

In order to determine the size of sponge particles in Nano dimensions, SEM device model no. S4160 made by HITACHI Company was used in Tehran University. Sponge was prepared in powdered form and their SEM pictures were obtained which show the size of particles in Nano scale. Also BET has taken. 


\subsubsection{Study of Kinetic}

In order to find the kinetic reaction, a certain amount of under study adsorbent, GH-92, has been put in contact with certain concentration of metal ions in different time duration; and the percentage and capacity of adsorption metal ions by adsorbent was evaluated.

\subsubsection{Study of Effect of Particle Size}

In order to study the effect of sponge particles size on the efficiency of adsorbent, at first stage the interested washed and dried sponge was ground and passed through sieves with 70,120 and 230 mesh grading. 0.1 gram70, 120 and 230 mesh sponge powder was added to $50 \mathrm{ml}$ solution containing lead metal ion in different concentration of 100, 200 and 300 $\mathrm{mg} /$ Liter. Then, under study solutions were filtered in $\mathrm{pH}$ of 4 to 5 and the amount of lead ion in solutions under the sieve has been measured by: atomic absorption spectroscopy device with flame.

\subsubsection{Study of Effect of Shaker}

In order to examine the effect of shaker on adsorption lead ion, Erlenmeyer containing $0.1 \mathrm{~g}$ sponge and mentioned ionic solutions with various concentration of 10, 25, 50, 100, 200, 250 and $300 \mathrm{mg} / \mathrm{Liter}$ related to lead ion were put on Shaker device for one hour with 150 rotation. Then the solutions were filtered and the amount of lead ion in solutions under the sieve has been measured by atomic absorption spectroscopy device with flame.

\subsubsection{Calculating Adsorption Capacity and Percentage}

To calculate interested adsorption capacity and percentage, we separated $0.1 \mathrm{~g}$ sponge and added various concentrations of metal ion $\mathrm{Pb}^{2+}$ in different conditions. Then, the solutions were filtered and adsorption was measured. In order to calculate adsorption capacity (1) was used:

$$
\mathrm{e}=\left[\left(\mathrm{C}_{\mathrm{o}}-\mathrm{C}_{\mathrm{i}}\right) \mathrm{v}\right] / \mathrm{m}
$$

Where $q_{e}$ is the amount of adsorbed metal ion in terms of mass adsorbent $\mathrm{mg} / \mathrm{g}, C_{0}$ initial concentration of metal ion, and $C_{1}$ secondary concentration of metal ion $\mathrm{mg} /$ liter and $\mathrm{V}$ is the volume of the solution in terms of liter, and $m$ the mass adsorbent in terms of gram. The percentage of absorption (2) was used:

$$
\left.\% \mathrm{p}=\left[\mathrm{C}_{\mathrm{o}}-\mathrm{C}_{\mathrm{i}}\right) / \mathrm{C}_{\mathrm{o}}\right]^{*} 100
$$

Where $\% p$ is absorption percentage, $C_{0}$, initial concentration of metal ion and $C_{1}$ secondary concentration of metal ion in $\mathrm{mg} / \mathrm{liter}$.

\section{Results}

\subsection{Determination of Sponge Nano-Particles Structure}

Obtained SEM images of sponge show that surface pores of sponge particles are in range of $500 \mathrm{~nm}$, which on the general structure there are also smaller pores with diameter about 18 to $80 \mathrm{~nm}$. (Figure 3) Also BET can confirm nanostructures sponges. (figure 4) (table 1)
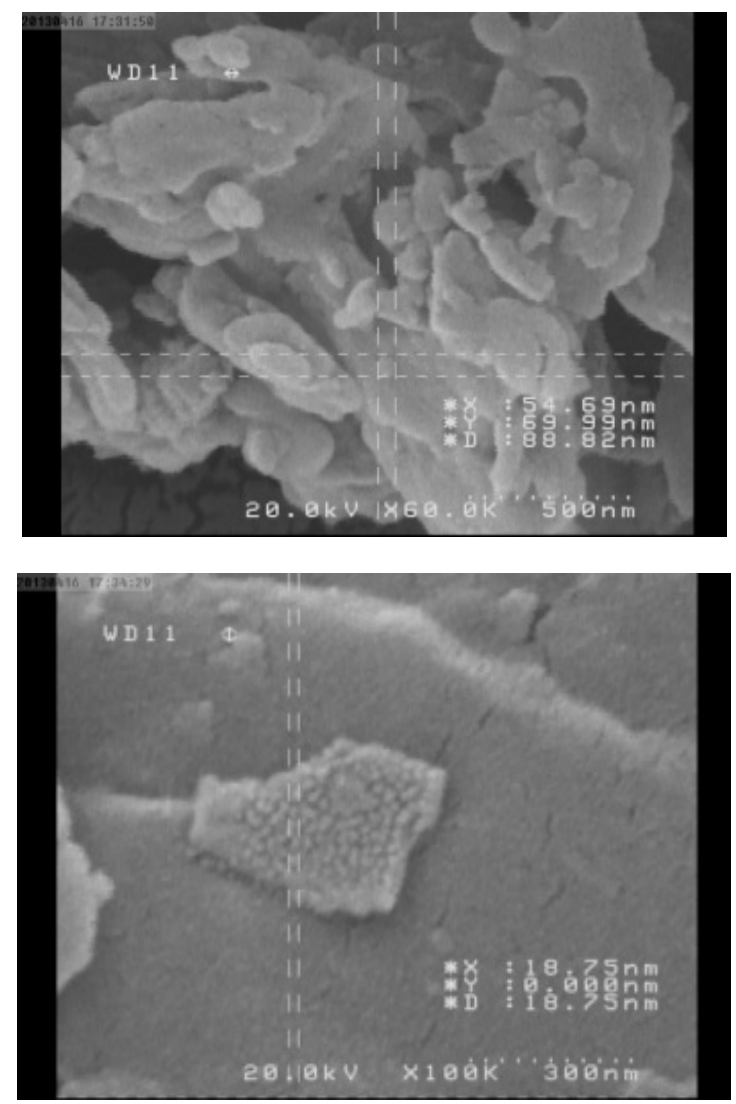

Figure 3. SEM images obtained from sponge with 120 mesh grading.

Table1. Single point BET.

\begin{tabular}{llll}
\hline Sponge & $\begin{array}{l}\text { Surface Area } \\
\mathbf{m}^{2} / \mathbf{g}\end{array}$ & $\begin{array}{l}\text { Pore Volume } \\
\mathbf{m l} / \mathbf{g}\end{array}$ & $\begin{array}{l}\text { Pore Diameter Dv } \\
\text { (d) } \mathbf{~ n m}\end{array}$ \\
\hline Demospongiae & 6.836 & 0.021 & 2.765 \\
\hline
\end{tabular}

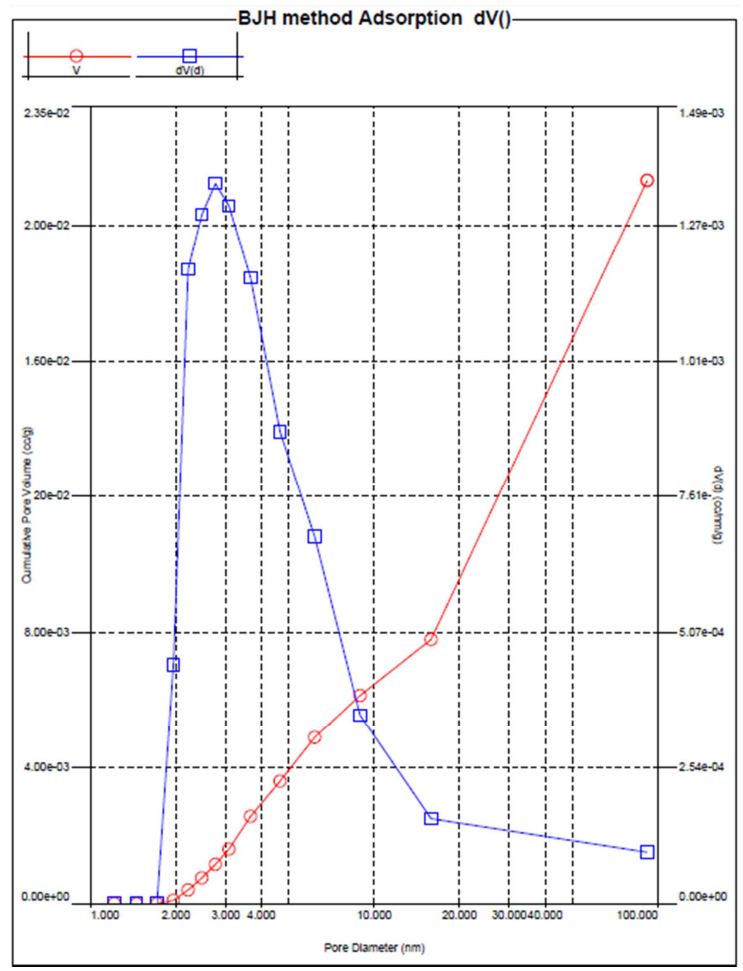

Figure 4. The results of BET from sponge. 


\subsection{Kinetic Reaction}

By increasing the contact time, due to rising the opportunity of clashing metal ions and adsorbent particles, the adsorption level will increase. Such function is observed for lead ion, contact time of adsorbent with metal ion has been considered between 1 to 24 hours, of which the highest adsorption capacity belongs to $250 \mathrm{ppm}$ concentration after 1 hours $43.72 \mathrm{mg} / \mathrm{g}$. (Figure 5)

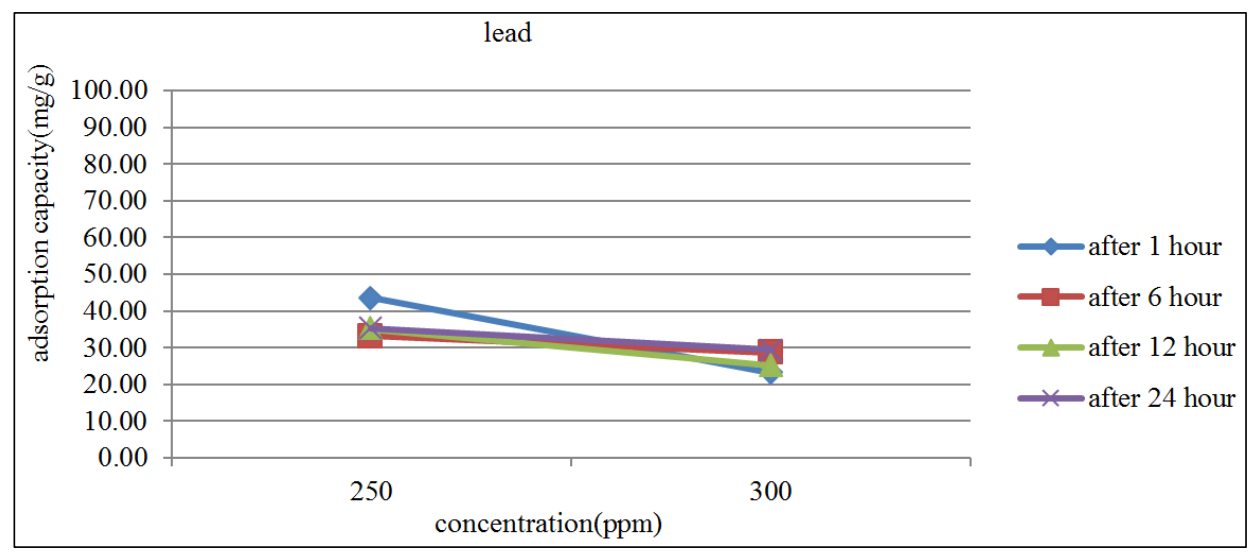

Figure 5. The effect of contact time on adsorption capacity of lead ion (adsorbent: sponge pieces).

The adsorption of calcium ions of 20,50 and $100 \mathrm{mg} / \mathrm{lit}$., magnesium of 10, 15, 20 and $100 \mathrm{mg} /$ lit., and cobalt of 5, 10, $25,50,100$ and $150 \mathrm{mg} /$ lit. was very little or negligible.

\subsection{The Size of Adsorbent Particles}

Increasing the adsorbent area will raise the amount of accessible positions and leads to higher level of adsorbent efficiency for removing metal ions. Through comparing the adsorbed level of lead ion by powdered sponge it is found that the under- study adsorbent has more ability for adsorbing lead ion with increasing the adsorbent area and the highest adsorption capacity belongs to $200 \mathrm{ppm}$ concentration after passing 4 hours with powdered sponge of 230 meshes grading that is $70.44 \mathrm{mg} / \mathrm{g}$. (Figures 6 to 8 )

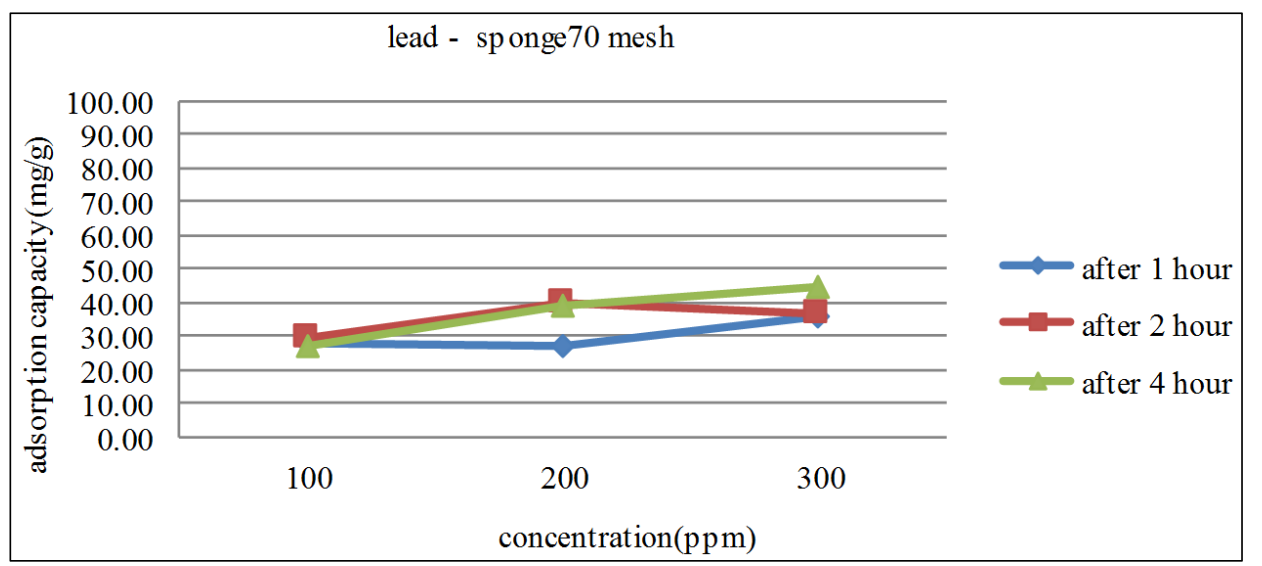

Figure 6. The effect of particle size and contact time on adsorption capacity of lead ion (adsorbent: 70- mesh sponge).

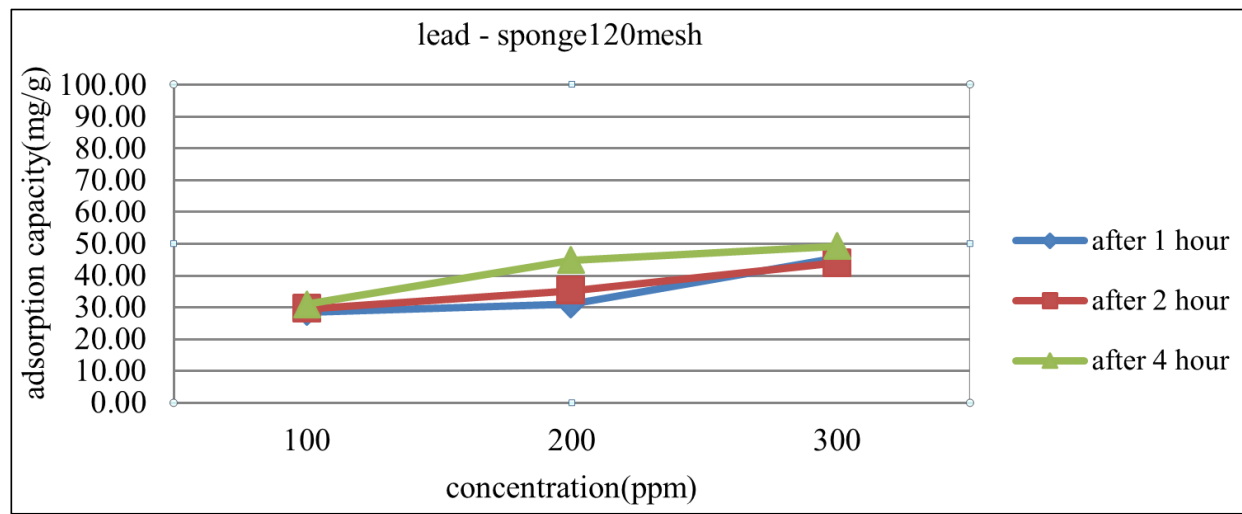

Figure 7. The effect of particle size and contact time on adsorption capacity of lead ion (adsorbent: 120- mesh sponge). 


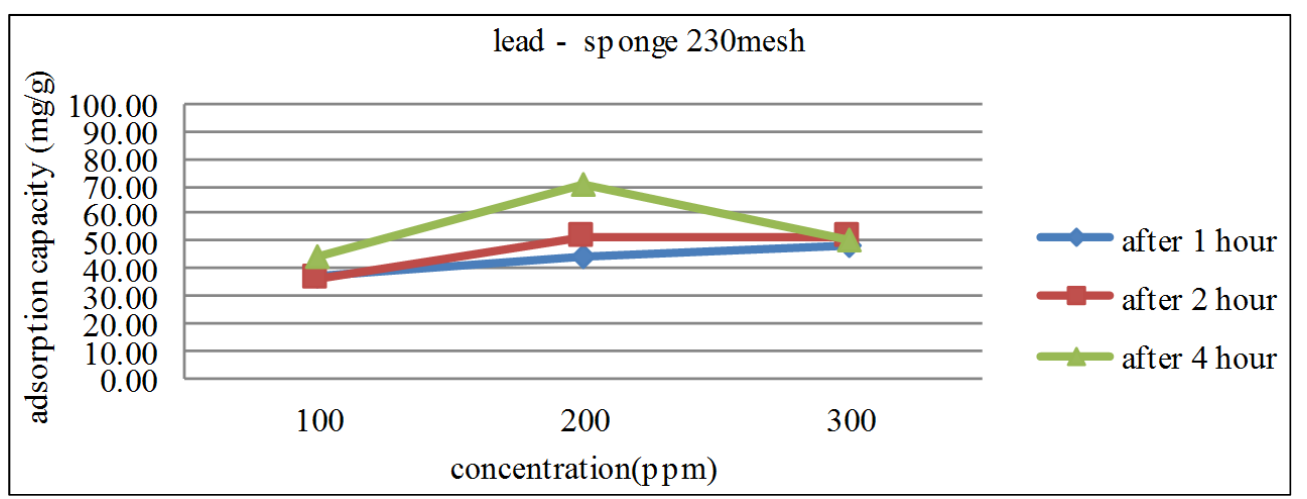

Figure 8. The effect of particle size and contact time on adsorption capacity of lead ion (adsorbent: 230- mesh sponge).

\subsection{The Effect of Shaker}

As it is shown in Figures 9 to 10, in Figure 9 the highest adsorption capacity for lead ion in 250 ppm concentration is 44.05 $\mathrm{mg} / \mathrm{g}$.

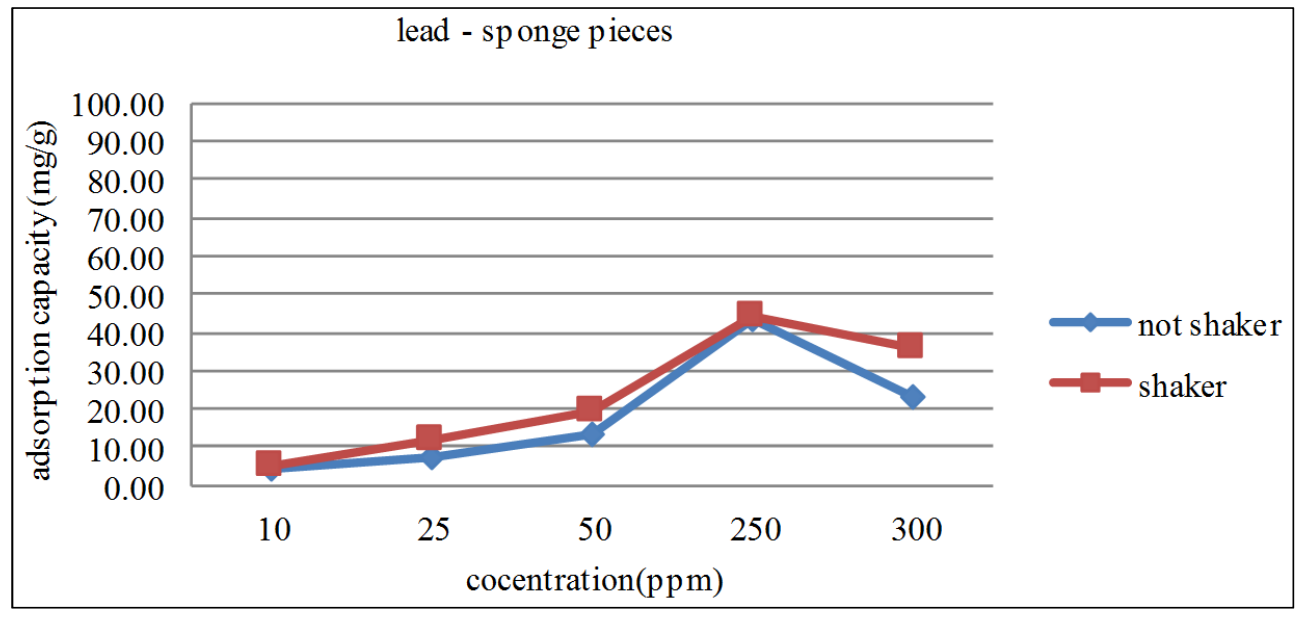

Figure 9. The effect of shaker on the absorption capacity of lead ion.

This adsorption decline in $300 \mathrm{ppm}$ concentration can be attributed to non-adsorption of ions (Figure 9). But the highest adsorption capacity belongs to lead ion of $300 \mathrm{ppm}$ concentration after passing 1hour with shaker next to powdered sponge of 230- mesh grading that is $79.19 \mathrm{mg} / \mathrm{g}$ (Figure 10 to 11 ).

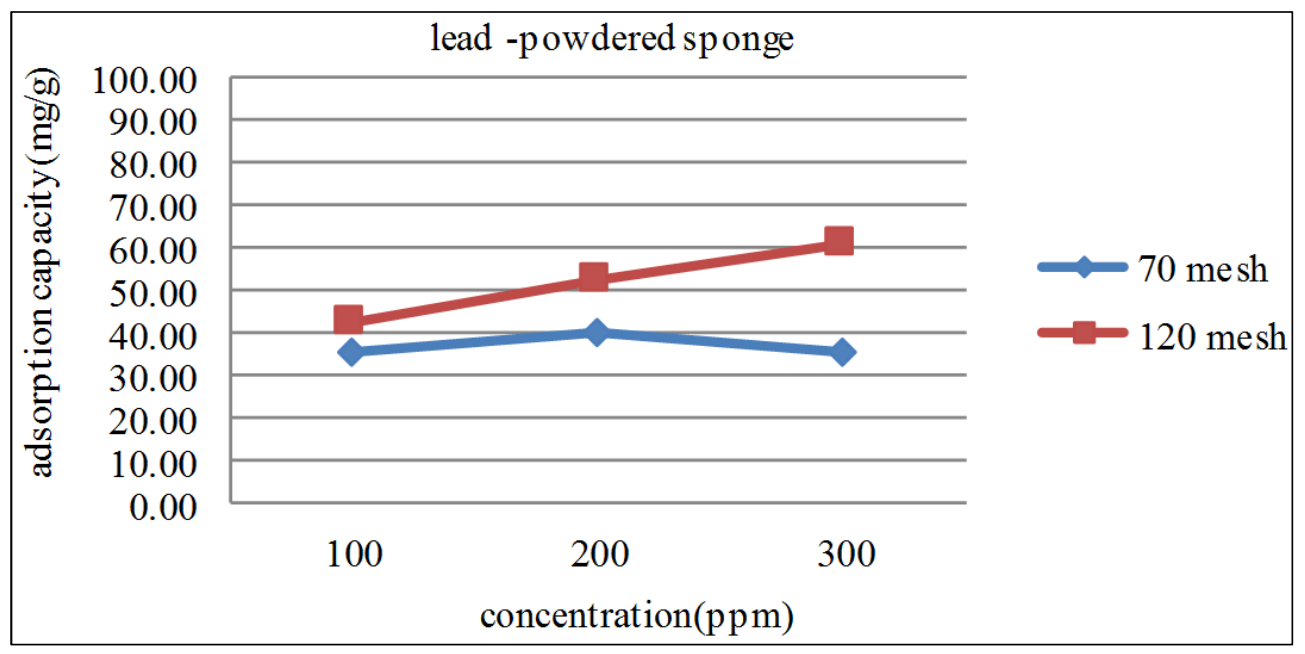

Figure 10. The effect of shaker on the adsorption capacity of lead ion (with powdered sponge). 


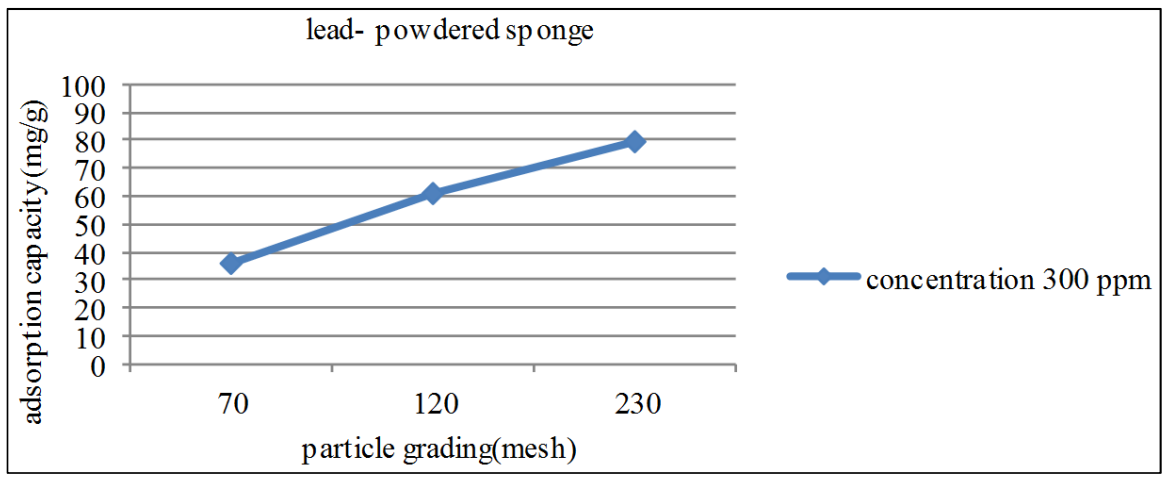

Figure 11. Adsorption capacity of lead ion with powdered sponge and various particle grading.

\subsection{Comparison of Adsorption Level in Sponge with Other Adsorbents}

In table 2, adsorption capacity of various adsorbents regarding adsorbing lead ion has been compared with each other.

Table 2. Comparison of maximum adsorption capacity in different adsorbents.

\begin{tabular}{llllll}
\hline \multirow{2}{*}{ Reference } & Maximum adsorption capacity (mg/g) & $\mathbf{p H}$ & $\begin{array}{l}\text { Metal } \\
\text { concentration } \mathbf{( m g / L )}\end{array}$ & $\begin{array}{l}\text { ion } \\
\text { amount }\end{array}$ & Adsorbent \\
\cline { 2 - 3 } & $\mathbf{P b}^{2+}$ & 6 & 100 & $5.2 \mathrm{mg} / \mathrm{L}$ & Chitosan nano- particles \\
\hline Ekhlasi, L; et al 2011 & 25.8 & 5 & 50 & $5 \mathrm{~g} / \mathrm{L}$ & $\mathrm{NH} \mathrm{H}_{2}-\mathrm{MCM}-41$ \\
Heidari, A; et al 2009 & 57.74 & - & - & - & Zeolite nano- adsorbent \\
Achanai Buasri et al 2008 & 58.73 & 5 & 300 & $0.1 \mathrm{~g}$ & Sponge \\
This research & 79.19 & & & & \\
\hline
\end{tabular}

\section{Discussion}

One of the important factors in adsorption level is the increase of contact time with adsorbent and moreover the results from the research have shown that adsorption level also depends on particle size. According to the results (Figures 5 to 8 ) by increasing the contact time, due to rising the opportunity and chance of clashing metal ions and adsorbent particles, the adsorption level will increase and also increasing the surface area will rise the amount of accessible positions and leads to higher level of adsorbent efficiency for removing or substituting metal ions. Experiments show that the amount of lead ion's adsorption capacity by small piece of sponge is $43.72 \mathrm{mg} / \mathrm{g}$ and by powdered sponge $44.70 \mathrm{mg} / \mathrm{g}$. Similarly we can point to comparison of adsorbed amount of cadmium and lead metal ions by powdered sponge, which under-study adsorbent has more ability in adsorbing lead ion. The reason can be attributed several factors such as chemical characteristic of adsorbent, physical structure of adsorbent, porosity, surface area, particle size as well as chemical nature of lead, molecular weight and the size of ionic radius (Figures 6 to 8). As it is shown in results figures (Figure 9), shaker can have considerable effect on absorbance percentage, since during shaker, due to rising the opportunity and chance of clashing metal ions with adsorbent particles, finally the adsorption level will increase. This adsorption rising has taken place for lead up to $250 \mathrm{ppm}$ concentration, that after which in higher concentration more than $250 \mathrm{ppm}$ a falling trend has been observed which can be resulted from ions' non-adsorption phase (Figure 9). But the highest adsorption capacity belongs to lead ion of $300 \mathrm{ppm}$ concentration after passing 1 hour with shaker next to powdered sponge of 230- mesh grading that is $79.19 \mathrm{mg} / \mathrm{g}$ (Figures 10 to 11). This adsorption rising can be explain by this reason that increasing more spaces in adsorbent's surface (230 meshes), has provided more effective area for adsorbing lead ions.

According to performed examinations by researchers on general applications of this type of sponge, in this study we tried to obtain the adsorb ability of calcium, magnesium, cobalt and lead ions by this sponge to be able to use this sponge as a practical tool in production of bio-filters used in water filtration. But experiments showed that this kind of sponge is not suitable for removing calcium, magnesium and cobalt. Hence, with regard to the obtained results it can be said that this adsorbent shows the highest level of adsorption for lead ion. Therefore, according to the obtained results, one can assess a practice to make adsorption columns or adsorption filters out of this type of sponge.

\section{Acknowledgements}

Authors deem necessary to appreciate Mrs. Engineer Vakili, the head of Research Laboratory of Marine Science and Technology IAU North Branch of Tehran and Mrs. Engineer Reza Zadeh, the head of Chemistry Research Laboratory.

\section{References}

[1] Achanai Buasri, Nattawut Chaiyut, Kittiya Phattarasirichot, Phetcharat Yongbut and Lalita Nammueng, Chiang Mai J. Sci. (2008). Use of Natural Clinoptilolite for the Removal of Lead (II) from Wastewater in Batch Experiment, 35 (3): 447-456. 
[2] Annadurai, G., Juang, R. S., and Lee, D .J. (2002). Use of cellulose -based wastes for adsorption of dyes from aqueous solutions, J. Hazard Matar. 92 (3) 263-274.

[3] Batista, D., Tellini, K., Nudi, A. H., Massone, T. P., de L. Scofield, A., and de L. R. Wagener, A. (2013). Marine sponges as bioindicators of oil and combustion derived PAH in coastal waters Marine Environmental Research, Volume 92, 234-24.

[4] Batzia, F. A., and Sidiras, D. K. (2004) .Dye adsorption by calcium-chloride treated beech sawdust in batch and fixedbed system .Water Res, 38 (13), 2967-2972.

[5] Bhattacharya, A. K., Naiya, T. K., Mandel, S. N., and Das, S. K. (2008). Adsorption, kinetics and equilibrium studies on removal of $\mathrm{Cr}$ (VI) from aqueous solutions using different low-cost adsorbents. J. Chem. eng. 137.3.529-541.

[6] Bhimba, V., Vinod, V., and Beulah, C (2013) Marine Sponge Sigmadocia pumila a potential supply for drug findings Journal of Pharmacy Research, Volume 6, Issue 4, 401-403.

[7] Cesar, R. T. T, Sergio, L. C. F., and Marco, A. Z. (2004). Use of modified rice husks as a natural solid adsorbent of trace metals: Characterization and development of an on-line pre concentration system for cadmium and lead determination by FAAS. J. Micro chem., 77, $163-175$.

[8] Cetin, s. and Pehliean, E. (2007). The use of fly ash as a low cost, environmentally friendly alternative to activated carbon for the removal of heavy metals from aqueous solutions. Colloid surface A, 298 (1-2) 87.

[9] Ekhlasi, L; Younesi, H; Mehraban, Z and Bahramifar, N. (2011). Synthesis and Application of Chitosan of Lead Ions from Aqueous Solutions. J. Water and Wastewater, 1: 10-18.
[10] Heidari, A; Younesi, H and Mehraban, Z. (2009). Removal of $\mathrm{Cd}$ (II), Ni (II) and $\mathrm{Pb}$ (II) Ions in an Aqueous Solution by Chemically Modified Nano porous MCM-41. J. Water and Wastewater, 1: 25-32.

[11] Lunder, M., Drevenšek, G., Hawlina, S., Sepčić, K., and Žiberna, L. (2012) Cardiovascular effects induced by polymeric 3-alkylpyridinium salts from the marine sponge Reniera sarai Toxicon, Volume 60, Issue 6, 1041- 1048.

[12] Mazaheri-Tehrani, M. (2012) Removal of toxic heavy metals: natural products as bio sorbents. J. feyz, 16 (7) $721-722$.

[13] Namasivaym, C., Kumar. M. D and Begum. R. A (2001). Waste coir pith - a potential biomass for the treatment of dyeing wastewaters Biomass Bioenerg21 (6) 477-483.

[14] Odoemelam, S. A., and Eddy, N. O. (2009). Studies on the use of oyster snail and periwinkle shells as adsorbents for the removal of $\mathrm{Pb}^{2+}$ from aqueous solution. J. of Chemistry, 6 (1), 213-222.

[15] Ozacar, M., Sidiras, D. K., and Sengil, I. A. (2005). Adsorption of metal complex dyes from aqueous solutions by pine sawdust. Bioresour. Technol., 96 (7), 791-795.

[16] Seader, J. D. and Henly, E. J. (2006). Separation process principles., $2^{\text {nd }}$ Ed., John Wiley and Sons, New York. Senthilkumar, K., Venkatesan, J., Manivasagan, P., and SeKwon Kim. (2013) Antiangiogenic effects of marine sponge derived compounds on cancer. Environmental Toxicology and Pharmacology, Volume 36, Issue 3, 1097- 1108.

[17] Zavvar Mousavi, S and Arjmandi, A. (2009). Removal of Heavy Metals Industrial Wastewater by Sheep Gut Waste. J. Water and Wastewater, 1: 63-68. 